\section{RECOMMEND A CLINICALLY PROVEN BREATH FRESHENER}

Oral malodour cannot be improved by tooth brushing alone $\mathrm{e}^{1}$ but if patients incorporate CB12 mouthwash into their oral hygiene routine, unpleasant smelling volatile sulphur compounds (VSCs) can be reduced.

$\mathrm{CB} 12$ oral health products contain

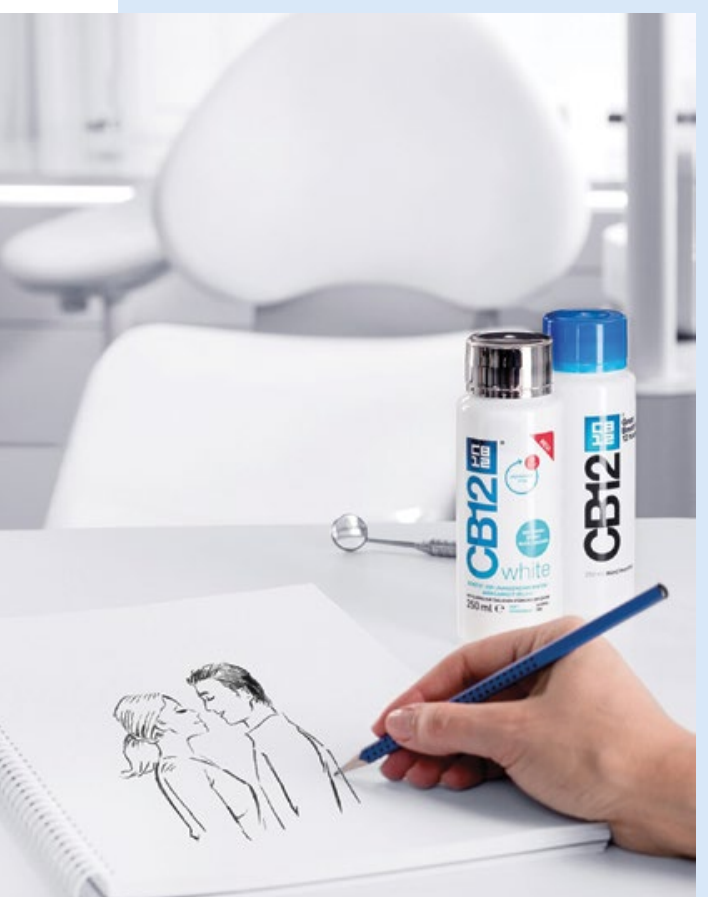

low concentrations of zinc acetate and chlorhexidine diacetate, a combination that has shown extraordinary efficacy by converting the offensive sulphur content of VSCs to odourless, insoluble sulphides and offering long lasting effects. ${ }^{2}$

Plus, CB12 mouthwash enhances the oral hygiene routine with anti-plaque agents and fluoride to prevent cavities and strengthen the teeth.

If you would like to recommend advanced, clinically proven oral health products to your patients, contact $\mathrm{CB} 12$ now.

For more information about CB12 and how it could benefit your patients, please visit www.cb12.co.uk.

\section{References}

1. Aung E.E, Ueno M, Zaitsu T. Furukawa S, Kawaguchi Y. Effectiveness of three oral hygiene regimens on oral malodour reduction. Trials 2015; 16: 31 .

2. Thrane P.S, Young A, Jonski G, Rölla G. A new mouthrinse combining zinc and chlorhexidine in low concentrations provides superior efficacy against halitosis compared to existing formulations: a double-blind clinical study. J Clin Dent 2007; 18: 82-86.

\title{
SHOW-STOPPING PRODUCTS IN BIRMINGHAM
}

The Waterpik stand was as popular as ever at the British Dental Conference and Dentistry Show 2019.

Delegates had the chance to see all the latest products on offer including the newest Waterpik Water Flosser models plus the ever popular Whitening Water

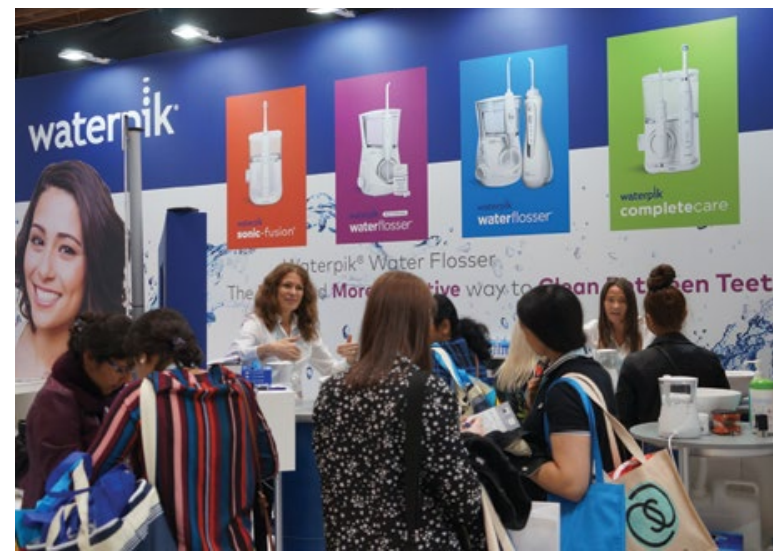

Flosser and Complete Care range. The star attraction was the Sonic-Fusion, the world's first and only flossing toothbrush; visitors were amazed by its oral healthcare benefits.

With products developed to improve and enhance your patient's home oral health routine, Waterpik is a resounding success.

If you missed the British Dental Conference and Dentistry Show but would like to learn more, contact the Waterpik team now.

For more information on Waterpik products visit www.waterpik.co.uk. Waterpik products are available from Amazon, Asda, Costco UK, Boots. com, Superdrug online and in stores across the UK and Ireland.

\section{THE UK'S FIRST BIOPLASTIC TONGUE CLEANER}

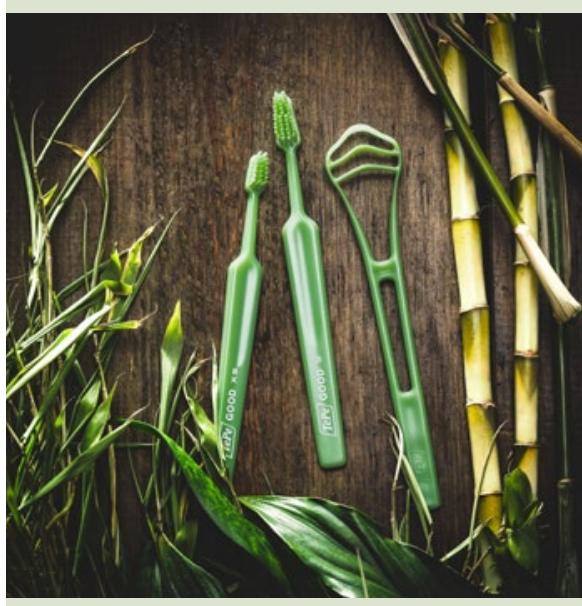

TePe has expanded its sustainably produced TePe GOOD range with the introduction of the TePe GOOD Compact toothbrush and TePe GOOD Tongue Cleaner, the UK's first bio-plastic tongue cleaner.

The TePe GOOD Compact toothbrush and TePe GOOD Tongue Cleaner are produced using renewable raw materials, sugar cane and castor oil. This enables TePe to recirculate up to $95 \%$ of the $\mathrm{CO}_{2}$ emissions during the products' life cycle, offering a more sustainable choice without compromising on product quality, design or hygiene.

The TePe GOOD Compact toothbrush and TePe GOOD Tongue Cleaner are manufactured using $100 \%$ green energy at TePe's Swedish Malmö factory, which has the largest solar power plant in the city.

The TePe GOOD Compact toothbrush has also been developed to ensure a highquality design, featuring an ergonomic handle, tapered head and rounded filaments for maximum cleanliness. It is recommended for children and adults who prefer a smaller brush head.

Furthermore, the new TePe GOOD Tongue Cleaner has been carefully designed to remove bacteria from the tongue. It corresponds to the natural shape of the tongue, making it easier to reach far back in the mouth, while the slim shape reduces the gag reflex. With three slightly raised cleaning surfaces for a triple-effect, one stroke should be enough to clean the tongue efficiently.

The TePe GOOD Compact toothbrush has a suggested retail price of $£ 2.75$, while TePe GOOD Tongue Cleaner has a recommended retail price of $£ 3.35$. 